\title{
Analysis on the use of non-resonant inverters in single-phase induction heating applications
}

\author{
Manuel Raeber, IEEE Member, Patrick Amiras, Andreas Heinzelmann \\ Institute for Energy Systems and Fluid Engineering (IEFE), School of Engineering \\ ZHAW Zurich University of Applied Sciences \\ 8400 Winterthur, Switzerland
}

\begin{abstract}
Induction heating plays an important role in industrial processes and is becoming increasingly important for household appliances such as induction cookers. Most commonly, series or parallel resonant circuits based on IGBT technology are used due to their low cost. In contrast to these, non-resonant converter types are described in this paper for the first time regarding their use in single-phase induction heating applications up to $2 \mathrm{~kW}$. The analysis is based on simulation and measurement results. The proposed non-resonant converter designs offer a very small size and allow full control of the output power. Different pulse pattern for controlling the induction power are investigated. It is found that the full-bridge inverter using block or PSM pulse pattern delivers the best performance and enough power capability. For the test system, the measured average electrical efficiency is $96.8 \%$ over the input power range of $500 \mathrm{~W}$ to $1750 \mathrm{~W}$.
\end{abstract}

Keywords - Induction heating, Induction cookers, Inductive power transfer

\section{INTRODUCTION}

Induction cookers and inductive cooktops are approximately $10 \%$ more efficient than conventional hotplates and help to save electrical energy in millions of households (see [1]). Instead of first transferring the heat energy to a plate or ceramic glass layer, the magnetic field generated by the induction coil is used to produce heat directly in the ferromagnetic bottom of the cookware as illustrated in Fig. 1. Eddy currents and magnetization losses both contribute to this effect and are simplified by a load resistor in the electrical model.

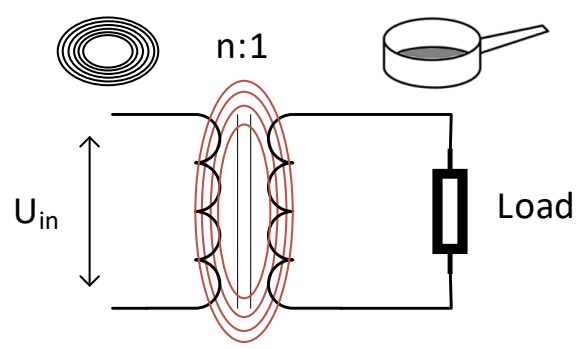

FIG. 1. WORKING PRINCIPLE OF AN INDUCTION COOKER WITH INDUCTION COIL (LEFT) AND COOKWARE AS ELECTRIC LOAD (RIGHT)
For decades, little has changed in induction technology. To achieve high coil currents, inductive heating applications are mostly based on series or parallel resonant circuits controlled by semiconductor switching devices such as Insulated-Gate Bipolar-Transistors (IGBT). An extensive review on induction heating technologies and applications is available in [2]. Improvements in IGBT technology and sophisticated control techniques, like zero current switching (ZCS) or zero voltage switching (ZVS), led to a constant reduction of power loss and left little need for further technical innovation. Low costs and high efficiency are undisputed advantages of resonant switching converters. However, concerning power control and space requirements there is room for improvement. For parallel resonant circuits, for example, the power is controlled usually by varying the ON/OFF time of the whole circuit in steps of several seconds.

In principle, for low power applications, there is no need for a resonant circuit. Full-bridge converters, as proposed for higher power levels in [3] and [4], would be able to drive an induction coil in a similar way, but high cost and losses have prevented their use in consumer applications. The recent developments in power electronics, especially wide-bandgap semiconductors, allow hard-switching methods at high frequencies and might be interesting for induction heating applications with power levels of some kilowatts.

This paper investigates direct inverter-fed, non-resonant induction heating methods. It proposes and compares different circuit topologies and pulse patterns. The paper is structured as follows: Section II summarizes relevant publications and Section III presents the analyzed circuits and control methods. In Section IV, the simulation and measurement setup are described in detail. The hardware prototype is shown in Section IV and Section V gives an overview of the measurement results and compares them to the simulation. Section VI concludes the findings and provides an outlook on future work.

\section{STATE OF THE ART}

Different electrical circuits for induction heating have been presented in the literature and are used in practice. In Table 1, 
the most important ones are listed. The minimum number of devices is stated in the third column. Instead of IGBTs, also MOSFETs could be used. The use of wide-bandgap devices in induction heating is currently being researched: GalliumNitride $(\mathrm{GaN})$ is proposed in [5] for a modular system running at $2 \mathrm{MHz}$. Silicon-Carbide ( $\mathrm{SiC}$ ) is employed for a full-bridge resonant converter in [6] and compared to IGBTs and SiMOSFETs in terms of efficiency in [7].

TABLE 1: OVERVIEW OF RESONANT CONVERTER TYPES USED FOR INDUCTION HEATING AND LIST OF POSITIVE/NEGATIVE FEATURES

\begin{tabular}{|c|c|c|c|}
\hline ID & Architecture & Components & Features \\
\hline 1 & $\begin{array}{l}\text { Parallel quasi-resonant } \\
\text { circuit [8] }\end{array}$ & $\begin{array}{l}1 \times \text { IGBT } \\
1 \times C_{r}\end{array}$ & $\begin{array}{l}\text { (+) Low cost } \\
(-) \text { High voltage rating of } \mathrm{C}_{\mathrm{r}} \\
\text { and IGBT } \\
\text { (-) Limited control }\end{array}$ \\
\hline 2 & $\begin{array}{l}\text { Series resonant half- } \\
\text { bridge [9], [10] }\end{array}$ & $\begin{array}{l}2 \times \mathrm{IGBT}^{2} \\
2 \mathrm{x} \mathrm{C}_{\mathrm{r}}\end{array}$ & $\begin{array}{l}\text { (+) High efficiency } \\
(-) \text { High voltage rating of } \mathrm{C}_{\mathrm{r}}\end{array}$ \\
\hline 3 & $\begin{array}{l}\text { Series resonant full- } \\
\text { bridge [11], [12] }\end{array}$ & $\begin{array}{l}4 \times \mathrm{IGBT} \\
1 \times \mathrm{C}_{\mathrm{r}}\end{array}$ & $\begin{array}{l}(+) \text { High efficiency } \\
(-) \text { Hardware effort }\end{array}$ \\
\hline 4 & $\begin{array}{l}\text { Other full-bridge } \\
\text { methods [3], [13] }\end{array}$ & $\begin{array}{l}4 \times \mathrm{IGBT} \\
1 \times \mathrm{C}_{\mathrm{r}}\end{array}$ & $(+)$ High power capability \\
\hline 5 & $\begin{array}{l}\text { Zero Voltage Switching } \\
\text { (ZVS) [14], [15] }\end{array}$ & $\begin{array}{l}1 \times \mathrm{IGBT} \\
1 \times \mathrm{C}_{\mathrm{r}}\end{array}$ & $(+)$ High efficiency \\
\hline 6 & $\begin{array}{l}\text { Zero Current } \\
\text { Switching (ZCS) [16] }\end{array}$ & $\begin{array}{l}1 \times \mathrm{IGBT} \\
1 \times \mathrm{C}_{\mathrm{r}}\end{array}$ & $(+)$ High efficiency \\
\hline
\end{tabular}

Different electrical models for the inductive energy transfer path are used in the literature (see [12], [17], [18], [19]): Transformer equivalent circuit (TEC), mutual inductance or a simplified series circuit with only $R$ and $L$ (series equivalent circuit SEC). Based on verification measurements it was decided to use the simplified TEC model shown in Fig. 2.

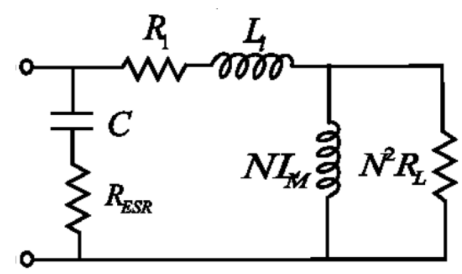

FIG. 2. TEC MODEL OF INDUCTION ENERGY TRANSFER [20]

\section{DESCRIPTION OF THE ANALYZED NON-RESONANT CIRCUITS}

Unlike the resonant methods referred to in the third and fourth row of Table 1, this paper proposes the use of full-bridge or half-bridge inverters to directly supply the induction coil. There is no need for a power factor correction (PFC) input as long as the input capacitance $C_{D C}$ is small, and the output power is allowed to oscillate at twice the grid frequency $(100 \mathrm{~Hz}$ or $120 \mathrm{~Hz}$ ). In the following subsections, the different converter types and control techniques are presented.

\section{A. Full-bridge inverter (FB)}

The full-bridge inverter shown in Fig. 3 allows either fundamental frequency pulsing or pulse-width modulation. The voltage rating of the IGBTs/MOSFETs and diodes is $U_{D C \max }$ ( $325 \mathrm{~V}$ in a $230 \mathrm{~V}$ grid). Therefore, widely available $600 \mathrm{~V}$ devices can be used.

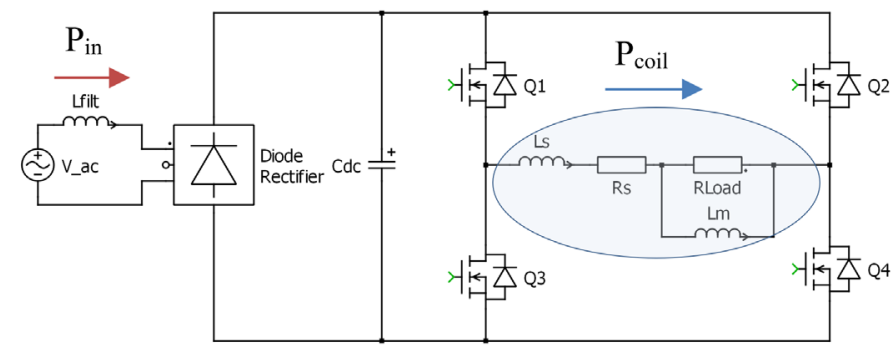

FIG. 3. INDUCTION HEATING CIRCUIT WITH DIODE RECTIFIER AND FULLBRIDGE INVERTER. THE INDUCTIVE POWER TRANSFER IS MODELLED AS AN EQUIVALENT R/L-CIRCUIT (BLUE OVAL).

\section{B. Half-bridge inverter $(H B)$}

Instead of a full-bridge inverter, a half-bridge inverter with two additional capacitors can be used. These capacitors are connected in series and replace the two switches $Q 2$ and $Q 4$. Unlike resonant capacitors, they are rated at half the DC-link voltage, are unipolar and not exposed to high voltage. Their capacity is higher compared to resonant capacitors to prevent the mid-point from shifting too much during switching operation. Compared to a full-bridge converter, the maximum achievable coil voltage is halved. Thus, another coil type must be used to keep the same power rating. The control and modulation options are similar to the full-bridge converter.

\section{Fundamental frequency pulsing}

The waveform applied to the induction coil is rectangular and the switching frequency equals the frequency of the induction current. The control signals of $Q 1 / Q 3$ and $Q 2 / Q 4$ are identical and vary between $0 \%$ and $50 \%$ to deliver the full range of output power. Only turn-off losses appear in the switching devices.

\section{Phase-shift modulation (PSM)}

Instead of varying the duty cycle of the pulses as in $\mathrm{C}$ ), for PSM, the phase shift between $Q 1$ and $Q 4$ (or $Q 2$ and $Q 3$, respectively) is varied between $0^{\circ}$ and $180^{\circ}$ to control the output power. Only turn-off losses appear in the switching devices.

\section{E. Pulse-width modulation (PWM)}

The coil current can be controlled by PWM to be sinusoidal. This control method has the drawback of increased losses. On one hand, the switching frequency is a multiple of the fundamental frequency and on the other hand, there are also turn-on losses including diode recovery losses. Pulse pattern optimization is possible to reduce switching losses. 


\section{METHOD}

This section presents the method used for the simulation and calculation of the circuit behavior and losses and the hardware prototype.

\section{A. Simulation setup}

The electric simulation was performed using the software tool PLECS (see Fig. 3). The corresponding simulation parameters are given in Table 2

TABLE 2: COMPONENT VALUES AND SETTINGS USED IN THE SIMULATION

\begin{tabular}{lll}
\hline \hline Parameter & Symbol & Value \\
\hline Induction heating model & - & $\mathrm{R}_{\mathrm{s}}=100 \mathrm{~m} \Omega, \mathrm{R}_{\mathrm{L}}=19 \Omega$ \\
& & $\mathrm{L}_{\mathrm{s}}=30 \mu \mathrm{H}, \mathrm{L}_{\mathrm{m}}=90 \mu \mathrm{H}$ \\
DC-Link capacitance & $C_{D C}$ & $10 \mu \mathrm{F}$ \\
Half-bridge capacitance & $C_{2,} C_{3}$ & $10 \mathrm{mF}$ \\
Rectifier diode forward & $V_{f}$ & $1 \mathrm{~V}$ \\
voltage & & \\
MOSFET & $Q 1 \ldots Q 4$ & $\mathrm{R}_{\mathrm{DS} \_ \text {on }}=70 \mathrm{~m} \Omega$ \\
Switching frequency & $f_{s}$ & $20 \mathrm{kHz}($ Fund., PSM) $/$ \\
& & $400 \mathrm{kHz}(\mathrm{PWM})$ \\
\hline \hline
\end{tabular}

\section{B. Efficiency calculation}

The overall converter efficiency is calculated according to (1). $P_{\text {in }}$ and $P_{\text {out }}$ are defined in Fig. 3. Forward losses of the diodes $P_{D}$, conduction losses $P_{C}$ and switching losses $P_{S w}$ of the MOSFETs/IGBTs, gate drive supply $P_{Q}$, rectifier forward losses and ohmic losses $P_{\text {Filt }}$ of the wiring and input filter are considered as shown in (2).

$$
\begin{gathered}
\eta=\frac{P_{\text {out }}}{P_{\text {in }}} \\
P_{V}=\left(P_{D}+P_{C}+P_{S w}+P_{Q}+P_{\text {Rect }}+P_{\text {Filt }}\right)
\end{gathered}
$$

With $P_{\text {out }}=P_{\text {in }}-P_{V}, \eta$ can be calculated for different operating points.

\section{Hardware prototype}

A hardware prototype with a power rating of $2 \mathrm{~kW}$ was built to verify the simulation results (see Fig. 4). The output power can be controlled stepless from 0 to $2 \mathrm{~kW}$. The prototype is equipped with three half-bridges of which two are used in the test setup. The SiC MOSFETs are mounted on a heat sink. They are driven with $15 \mathrm{~V}$ and controlled via a $3 \mathrm{~V}$ PWM input. From the left side, the DC-link is supplied by either AC or DC. The induction coil is connected to the $\mathrm{AC}$ output on the right.

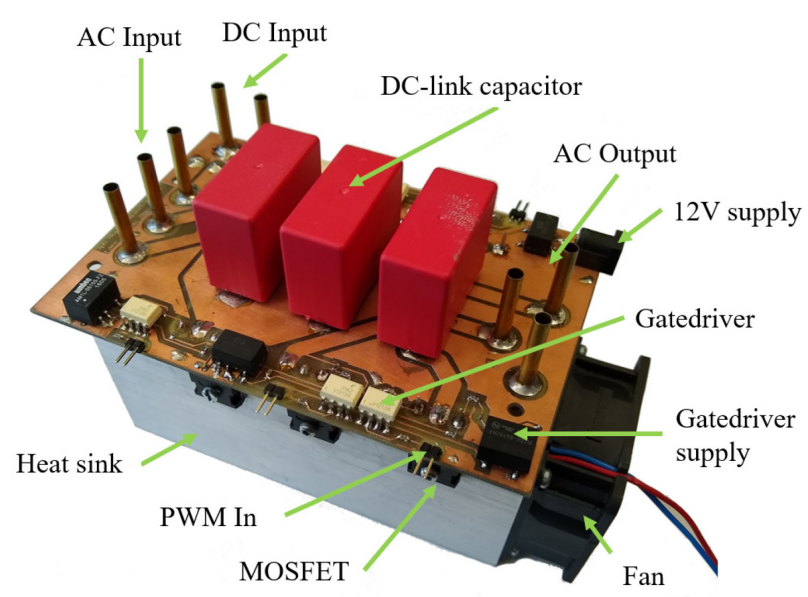

Fig. 4. HARDWARE PROTOTYPE WITH SiC MOSFETS

The used components are specified in Table 3. With the identical hardware setup, any standard MOSFET or IGBT could be used instead of the SiC devices. The induction coil was taken from a commercial induction cooker.

\begin{tabular}{|c|c|c|}
\hline Parameter & Symbol & Value \\
\hline Induction coil & $L_{\text {Ind }}$ & $\begin{array}{l}26 \text { turns, litz wire, with ferrites } \\
\text { (from cooker: PC-EKI 1016) }\end{array}$ \\
\hline DC-Link capacitor & $C_{D C}$ & $10 \mu \mathrm{F}, \mathrm{FKP} 4$ \\
\hline Diode rectifier & $D$ & $30 \mathrm{~A} / 800 \mathrm{~V}$ \\
\hline MOSFET & $Q 1 \ldots Q 4$ & $\begin{array}{l}\text { Wolfspeed C3M0065090D } \\
(900 \mathrm{~V} / 35 \mathrm{~A})\end{array}$ \\
\hline Isolated gate driver & $U 1 \ldots U 4$ & 2 A optocoupler \\
\hline Gate driver supply & $G 1 \ldots G 3$ & Isolated DC/DC $15 \mathrm{~V} / 1 \mathrm{~W}$ \\
\hline Heat sink & - & Fischer Elektronik LA6 15012 \\
\hline Line filter & $L_{\text {Filt }}$ & $250 \mu \mathrm{H} / 50 \mathrm{~m} \Omega$ \\
\hline Switching frequency & $f_{s}$ & $20 \mathrm{kHz}$ \\
\hline
\end{tabular}

TABLE 3: COMPONENTS AND OPERATION SETTINGS OF THE PROTOTYPE

\section{RESULTS}

This chapter presents the simulation and measurement results. Where applicable, the same component values were used in the simulation and the hardware prototype.

\section{A. Simulation results}

Fig. 5 shows the simulated induction coil voltage and current for three different pulse patterns: Fundamental frequency pulsing with $D=40 \%$, PSM with a phase shift of $\varphi=60^{\circ}$ and $\mathrm{PWM}$ at $400 \mathrm{kHz}$ with $m=1$. For fundamental frequency pulsing and PSM, the current amplitude is just below $40 \mathrm{~A}$, whereas for PWM, it is almost halved. Therefore, the output power of PWM is considerably lower. The simulation results are summarized in Table 5. The efficiency cannot be derived directly from the simulation results. Therefore, the calculation presented in Section IV.B was used assuming the simulated current and voltage values. 

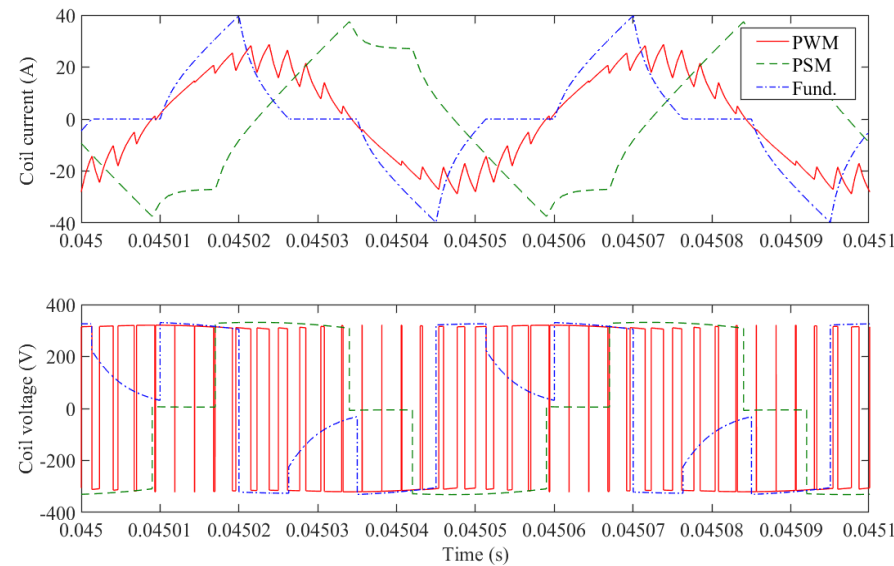

FIG. 5. SiMULATION OF COIL CURRENT AND VOLTAGE FOR DIFFERENT PULSE PATTERNS (SEE SECTION III)

\section{B. Measurements}

Input and output voltage and current of the prototype were measured to determine power values, the efficiency and the input power factor. The measurement can be compared directly to the simulation output. The measuring instruments used are listed in Table 4. The half-bridge topology is not able to deliver the requested coil current and is not selected for being tested in a measurement. From the remaining methods, PSM shows the highest efficiency at the analyzed operating conditions. Therefore, only this method is tested in the measurement.

TABLE 4: MEASUREMENT EQUIPMENT

\begin{tabular}{lll}
\hline \hline Device & Manufacturer & Type \\
\hline Oscilloscope & Lecroy & HDO4034A \\
Current meter & Lecroy & CP030 \\
Voltage meter & Lecroy & HVD3106 \\
Power analyzer & Infratek & 108A \\
Function generator & Active Technologies & AT-AWG1104 \\
\hline \hline
\end{tabular}

$108 \mathrm{~A}$ accuracy for $20 \mathrm{kHz}$ and $40 \mathrm{~A}$ range: $0.2 \% \mathrm{Rdg}+1 \% \mathrm{FS}$

In Fig. 6 the measured input voltage and current of the prototype running at the simulated operating conditions of PSM is shown. The data corresponds to the green dotted lines of voltage and current in Fig. 5. The prototype was connected to the grid by means of a line inductor specified in Table 2 . Input and coil power, coil current, efficiency and the power factor (PF) of the input current are measured directly by the power analyzer. These values are given in Table 5 and compared to the simulation output.
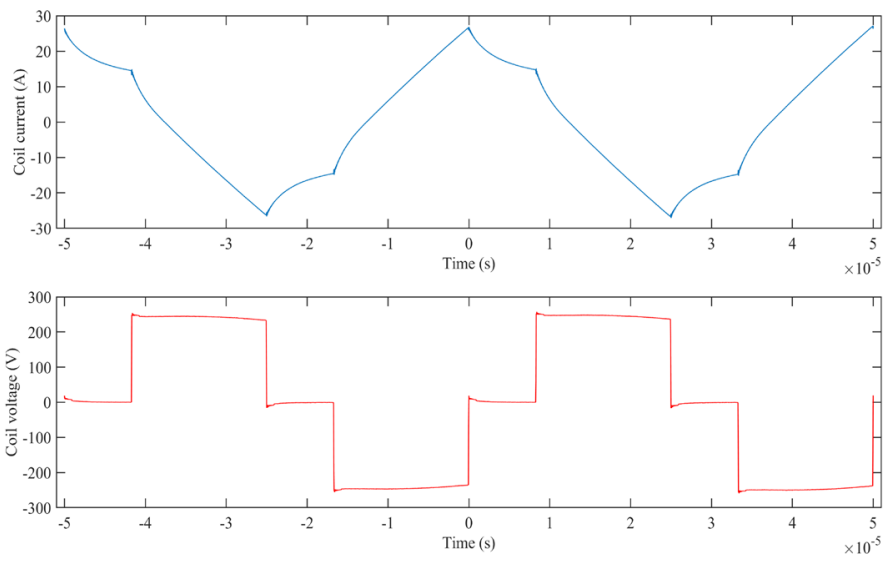

FiG. 6. MEASUREMENT OF COIL CURRENT (BLUE) AND COIL VOLTAGE (RED) FOR $230 \mathrm{~V}$ INPUT AND PSM WITH $60^{\circ}$ PHASE SHIFT

\section{CONCLUSION}

This paper proposes the use of full- and half-bridge inverters to directly supply the coil of an induction heating device. Three different pulse patterns are analyzed by electric simulation. Compared to full-bridge, half-bridge circuits have the drawback of a reduced output power due to a lower voltage applied to the induction coil. In the given test setup, the coil inductance would need to be approximately one fourth to achieve the same output power.

It was found that the fundamental pulse and PSM methods show the best performance. PWM methods suffer from a low efficiency due to high switching losses, mainly from turn-on and reverse-recovery. The electrical system simulation and the hardware test measurements confirm the good controllability and low complexity of the shown methods.

The measured efficiency value is $0.3 \%$ above the calculated one. However, power measurements with the Infratek 108A at $20 \mathrm{kHz}$ are subject to a reduced accuracy of approx. $1.2 \%$. The measured efficiency of the hardware prototype including filter losses is $96.8 \%$ over the input power range of $500 \mathrm{~W}$ to $1750 \mathrm{~W}$.

Future work is necessary to improve the simulation model of the inductive energy transfer. Only one set of induction coil and cookware has been used and modelled. Whether or not it makes sense to use non-resonant induction converters instead of conventional ones depends on the application requirements and applicable standards since the effect on electromagnetic compatibility has not yet been investigated.

TABLE 5: COMPARISON OF SIMULATION OUTPUT AND MEASUREMENT RESULTS AT $230 \mathrm{~V}$

\begin{tabular}{|c|c|c|c|c|c|c|}
\hline \multirow[t]{2}{*}{ Parameter } & \multirow{2}{*}{$\begin{array}{l}\text { FB Fundamental } \\
(D=0.4) \\
\text { Simulation }\end{array}$} & \multirow{2}{*}{$\begin{array}{l}\text { FB PWM } \\
(m=1) \\
\text { Simulation }\end{array}$} & \multirow{2}{*}{$\begin{array}{l}\text { HB Fundamental } \\
(D=0.4) \\
\text { Simulation }\end{array}$} & \multirow{2}{*}{$\begin{array}{l}\text { HB PWM } \\
(\boldsymbol{m}=\mathbf{1}) \\
\text { Simulation }\end{array}$} & \multicolumn{2}{|c|}{ FB PSM $\left(\varphi=60^{\circ}\right)$} \\
\hline & & & & & Simulation & Measurement \\
\hline Input power $P_{\text {in }}$ & $1393 \mathrm{~W}$ & $812 \mathrm{~W}$ & $341 \mathrm{~W}$ & $201 \mathrm{~W}$ & $1229 \mathrm{~W}$ & $1228 \mathrm{~W}$ \\
\hline Input voltage $U_{\text {in }}$ & $225 \mathrm{~V}$ & $225 \mathrm{~V}$ & $225 \mathrm{~V}$ & $225 \mathrm{~V}$ & $225 \mathrm{~V}$ & $224 \mathrm{~V}$ \\
\hline Power factor $P F$ & - & - & - & - & - & 0.99 \\
\hline Coil current $\mathbf{I}_{\text {coil }}$ & $15.7 \mathrm{~A}$ & $12.2 \mathrm{~A}$ & $7.9 \mathrm{~A}$ & $6.10 \mathrm{~A}$ & $15.1 \mathrm{~A}$ & $14.1 \mathrm{~A}$ \\
\hline Coil power $\mathbf{P}_{\text {coil }}$ & - & - & - & - & - & $1202 \mathrm{~W}$ \\
\hline Efficiency $\eta$ & 0.975 & 0.807 & 0.975 & 0.810 & 0.975 & 0.978 \\
\hline
\end{tabular}




\section{REFERENCES}

[1] M. Sweeney, J. Dols, B. Fortenbery, and F. Sharp, "Induction Cooking Technology Design and Assessment," ACEEE Summer Study Energy Effic. Build., p. 10, 2014.

[2] O. Lucia, P. Maussion, E. J. Dede, and J. M. Burdio, "Induction Heating Technology and Its Applications: Past Developments, Current Technology, and Future Challenges," IEEE Trans. Ind. Electron., vol. 61, no. 5, pp. 2509-2520, May 2014, doi: 10.1109/TIE.2013.2281162.

[3] A. Kumar, P. K. Sadhu, R. Raman, and J. Singh, "Design Analysis of Full-Bridge Parallel Resonant Inverter for Induction Heating Application Using Pulse Density Modulation Technique," in 2018 International Conference on Power Energy, Environment and Intelligent Control (PEEIC), Greater Noida, India, Apr. 2018, pp. 398 402, doi: 10.1109/PEEIC.2018.8665571.

[4] G. M. Segura, "Induction heating converter's design, control and modeling applied to continuous wire heating," Universitat Politecnica de Catalunya, 2012.

[5] H. Sarnago, J. M. Burdio, and O. Lucia, "High-Frequency GaN-Based Induction Heating Versatile Module for Flexible Cooking Surfaces," in 2019 IEEE Applied Power Electronics Conference and Exposition (APEC), Anaheim, CA, USA, Mar. 2019, pp. 448-452, doi: 10.1109/APEC.2019.8721779.

[6] M. Perez-Tarragona, H. Sarnago, O. Lucia, and J. M. Burdio, "Fullbridge series resonant multi-inverter featuring new $900-\mathrm{V} \mathrm{SiC}$ devices for improved induction heating appliances," in 2016 IEEE Applied Power Electronics Conference and Exposition (APEC), Long Beach, CA, Mar. 2016, pp. 1762-1766, doi: 10.1109/APEC.2016.7468106.

[7] S. Aslan, M. Ozturk, and N. Altintas, "A comparative study of SiC and $\mathrm{Si}$ power devices in induction cookers," in 2018 5th International Conference on Electrical and Electronic Engineering (ICEEE), Istanbul, May 2018, pp. 297-301, doi: 10.1109/ICEEE2.2018.8391350.

[8] I. Nam, "Analysis and design method for parallel quasi resonant inverter in induction heating applications," in 2018 IEEE Applied Power Electronics Conference and Exposition (APEC), San Antonio, TX, USA, Mar. 2018, pp. 1959-1967, doi: 10.1109/APEC.2018.8341286.

[9] S. R. Ghuge and M. R. Roda, "Summary of overall topologies of an induction cooker for home use (298)," in 2015 International Conference on Energy Systems and Applications, Pune, India, Oct. 2015, pp. 655-657, doi: 10.1109/ICESA.2015.7503431.

[10] H. W. Koertzen, J. D. van Wyk, and J. A. Ferreira, "Design of the halfbridge, series resonant converter for induction cooking," in Proceedings of PESC '95 - Power Electronics Specialist Conference,
Atlanta, GA, USA, 1995, vol. 2, pp. 729-735, doi: 10.1109/PESC.1995.474899.

[11] A. Nanda, A. Kar, and M. Sengupta, "Design, Analysis, Simulation, Fabrication and Experiments on a Voltage Source Inverter Fed Induction Heating Prototype," in 2018 IEEE International Conference on Power Electronics, Drives and Energy Systems (PEDES), Chennai, India, Dec. 2018, pp. 1-6, doi: 10.1109/PEDES.2018.8707732.

[12] J. M. Burdio, F. Monterde, J. R. Garcia, L. A. Barragan, and A. Martinez, "A Two-Output Series-Resonant Inverter for InductionHeating Cooking Appliances," IEEE Trans. Power Electron., vol. 20, no. 4, pp. 815-822, Jul. 2005, doi: 10.1109/TPEL.2005.850925.

[13] S.-S. Choi, C.-W. Lee, I.-D. Kim, J. H. Jung, and D. H. Seo, "New Induction Heating Power Supply for Forging Applications Using IGBT Current-Source PWM Rectifier and Inverter," in 2018 21st International Conference on Electrical Machines and Systems (ICEMS), Jeju, Oct. 2018, pp. 709-713, doi: 10.23919/ICEMS.2018.8549080.

[14] S. Wang, K. Izaki, I. Hirota, H. Yamashita, H. Omori, and M. Nakaoka, "Induction-heated cooking appliance using new quasi-resonant ZVSPWM inverter with power factor correction," IEEE Trans. Ind. Appl., vol. 34, no. 4, pp. 705-712, Aug. 1998, doi: 10.1109/28.703961.

[15] P. Achara, P. Viriya, and K. Matsuse, "Analysis of a Half - Bridge Inverter for a Small-Size Induction Cooker Using Positive-Negative Phase-Shift Control under ZVS and NON-ZVS Operation," in 2007 7th International Conference on Power Electronics and Drive Systems, Bangkok, Thailand, Nov. 2007, pp. 157-163, doi: 10.1109/PEDS.2007.4487695.

[16] M. Leisten and L. Hobson, "A PARALLEL RESONANT POWER SUPPLY FOR INDUCTION COOKING USING A GTO,” presented at the 1990 Fourth International Conference on Power Electronics and Variable-Speed Drives, Jul. 1990, p. 7.

[17] B. Hesterman, "Analysis and Modeling of Magnetic Coupling," presented at the Denver Chapter, IEEE PES, Boulder, Colorado, Apr. $10,2007$.

[18] L. Takau and P. Bodger, "Low frequency modelling of induction heaters using series equivalent circuit, transformer equivalent circuit and finite element analysis," in 2013 Australasian Universities Power Engineering Conference (AUPEC), Hobart, Australia, Sep. 2013, pp. 1-6, doi: 10.1109/AUPEC.2013.6725426.

[19] ON Semiconductor, “AND9166 Induction Cooking.” Oct. 2014.

[20] J. Lee, S. Lim, K. Nam, and D. Choi, "Design Method of an Optimal Induction Heater Capacitance for Maximum Power Dissipation and Minimum Power Loss Caused by ESR," IFAC Proc. Vol., vol. 37, no. 15, pp. 463-469, Sep. 2004, doi: 10.1016/S1474-6670(17)31068-6. 